\title{
AN EVALUATION OF GAS INJECTION EFFECTS IN A MECHANICALLY STIRRED HOT METAL DESULFURIZATION SYSTEM
}

\author{
Filipe de Menezes Torres ' \\ Carlos Antonio da Silva ${ }^{2}$ \\ Itavahn Alves da Silva ${ }^{2}$ \\ Pedro Henrique Resende Vaz de Melo ${ }^{2}$ \\ Marcelo Araújo Lourenço ${ }^{2}$
}

\begin{abstract}
Physical modeling techniques have been used in order to assess the effects of gas injection as a means of optimizing mechanically stirred desulfurization processes. For such a 1:7 scale model of a 315 ton of a Kanbara reactor was built. The influence of gas injection on mixing times, gas - liquid interfacial kinetics and solid phase dispersion was evaluated. Gas injection can reduce mixing times up to $20 \%$ and can increase solid dispersion up to $40 \%$. Gas liquid interaction is shown to be highly dependent on the gas injection location. In this regard injecting through the impeller or at the bottom of the ladle has been investigated. Gas injection can be beneficial to the desulfurization process.
\end{abstract}

Keywords: Kanbara Reactor; Desulfurization; Gas injection; Stirred tank.

\section{UMA AVALIAÇÃO DOS EFEITOS DA INJEÇÃO DE GÁS EM UM SISTEMA MECANICAMENTE AGITADO DE DESSULFURAÇÃO DE FERRO GUSA}

\section{Resumo}

Técnicas de simulação física foram utilizadas para analisar os efeitos da injeção de gás como modo de otimização de processos de dessulfuração mecanicamente agitados. Um modelo em escala 1/7, correspondente a um reator de 315ton de capacidade, foi desenvolvido. O estudo foi realizado por meio da análise do tempo de mistura, cinética de interação interfacial e qualidade da dispersão de escória. Resultados satisfatórios foram observados, como uma redução de até $20 \%$ do tempo de mistura e um aumento de $40 \%$ na dispersão de escória para o fundo da panela. A interação gás - líquido é altamente dependente do local de injeção de gás. A técnica possui grande potencial de otimização do processo. Palavras-chave: Reator Kanbara; Dessulfuração; Injeção de gás; Tanque agitado.

\section{INTRODUCTION}

Fast homogenization and adequate interaction between the desulfurizing agent and liquid metal are important factors as far as the efficiency of a desulfurization is concerned. For this reason, Kanbara Reactor (KR process) stands out as one of the most feasible options to obtain minimum sulfur content in steels [I]. Gas injection is common practice in desulfurization processes. Magnesium mono-injection, for example, uses $\mathrm{N}_{2}$ as a gas carrier of $\mathrm{Mg}$ granules. Co-injection, a more efficient technique and a standard worldwide, uses a mixture of reagents, which combines the fast desulfurization and deoxidation of magnesium with low final sulphur concentrations promoted by lime, also by means of a carrier gas [I].

Hydrocarbon blowing is a technique that can benefit the desulfurization process, since it leads to decreasing oxygen activities in the bath [2]. It has been shown that propane injection in both KR and torpedo car can result in reduction of desulfurizing agent consumption. It was noticed

'Rede Temática em Engenharia de Materiais - REDEMAT, Universidade Federal de Ouro Preto - UFOP, Ouro Preto, MG, Brazil.

E-mail: filipemtgv@gmail.com

${ }^{2}$ Departament of Metallurgical Engineering, Universidade Federal de Ouro Preto - UFOP, Ouro Preto, MG, Brazil.

2176-1523 (C) 2016 Associação Brasileira de Metalurgia, Materiais e Mineração. Published by ABM. This is an open access paper, published under the Creative Commons CC BY-NC-ND license (Attribution-NonCommercial-NoDerivs) - https://creativecommons.org/licenses/ by-nc-nd $/ 4.0 \%$ 
a $20 \%$ reduction which corresponded to a $16 \%$ decrease in the total cost. This better performance is also attributed to the higher stirring energy allowed by the bubbles.

The size and adequate dispersion of bubbles are critical factors for the efficiency of refining processes when gas injection is employed [3]. Therefore, disintegration and dispersion of bubbles are promising areas of study. In these type of reactors, the configuration of gas injectors is important factor for efficiency [4].

Previous works have discussed aspects related to gas dispersion and particle dispersion in stirred tanks, separately. Their results are specific of a given metal and geometry since thermodynamic and kinetic requirements are dictated by the refining objectives. This work presents a comprehensive discussion of the effects of gas injection on mixing, gas - liquid reaction and particle dispersion in mechanically stirred ladle intended for hot metal desulphurization. These aspects are important since they help to define reagent yield and then the economic feasibility

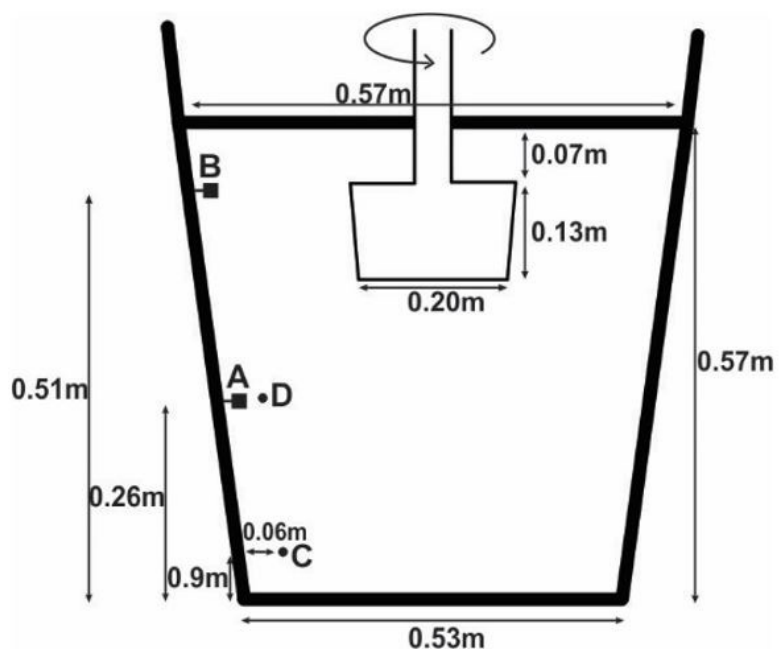

Figure I. Model representation and respective dimensions.

\section{MATERIALS AND METHODS}

An acrylic model of a 3 I 5-ton capacity mechanically stirred desulfurization reactor was built following a I/7 geometric scale. Model main dimensions are shown in Figure I.

Similarity between the water model and the industrial operation is an important issue. According to Bird et al. [5], impeller velocity and liquid viscosity should be chosen in agreement with Reynolds and Froude numbers. They lead to restrictions presented in Equations I and 2.

$$
\begin{aligned}
& N_{P} / N_{M}=\left(D_{M} / D_{P}\right)^{1 / 2} \\
& v_{P} / v_{M}=\left(D_{P} / D_{M}\right)^{3 / 2}
\end{aligned}
$$

Here, $N$ is the rotation velocity of the impeller, $D$ is the impeller diameter, $v$ is the liquid kinematic viscosity, and $P$ and $M$ denote prototype and model, respectively.

It can be shown that in order to simultaneously abide to both criteria a liquid of unreasonably low value of viscosity should be chosen. Thus, Froude number is suggested in order to achieve the same shape of liquid gas interface.

Gas flow rates were determined based on modified Froude number criterion [6], which describes the dynamics of bubbles, as stated in Equation 3.

$$
\rho_{P} Q_{P}^{2} / \rho_{l, P} d_{P}{ }^{4} D_{P}=\rho_{M} Q_{M}^{2} / \rho_{l, M} d_{M}{ }^{4} D_{M}
$$

Where $\rho$ is the gas density, $\rho_{L}$ is the liquid density, $Q$ is the gas flow rate, $D$ is the impeller diameter, and $d$ is nozzle diameter. $\mathrm{P}$ and $\mathrm{M}$ denote prototype and model, respectively.

Thereby, three different gas injection arrangements have been tried, see Figure 2. Total gas flow rates were 10,20 and $30 \mathrm{~L} / \mathrm{min}$, and impeller rotational speeds were 100, 120, 140 and 160rpm.

Mixing behavior was evaluated by following the dispersion of a $\mathrm{KCl}$ saturated water solution tracer added at bath surface. Mixing was taken as complete when conductivity signals acquired through conductivity probes located at points $A$ and $B$ (Figure I) stabilized within a $\pm \% 5$

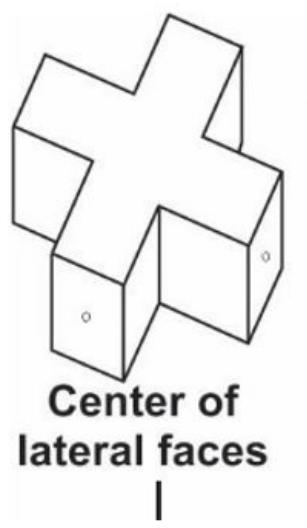

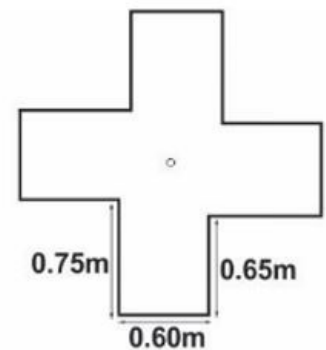

Base center

II

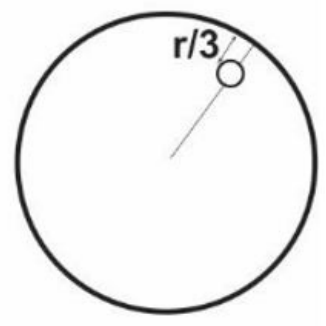

Ladle bottom

III

Figure 2. Injection arrangements. 
range of nominal concentration. Details of this technique are given elsewhere [7].

Some features of gas metal reaction kinetics have been evaluated by an absorption-desorption technique as described by Guo [8]. Carbon dioxide was first absorbed into a slightly caustic solution $(0.02 \mathrm{~mol} / \mathrm{L} \mathrm{NaOH})$. Despite the presence of species such as $\mathrm{HCO}_{3}^{-}$and $\mathrm{CO}_{3}^{2-}$, only $\mathrm{CO}_{2}$ concentration varies significantly in a 6 to $8.5 \mathrm{pH}$ range. $\mathrm{pH}$ and $\mathrm{CO}_{2}$ concentration can be readily related to each other through thermodynamic calculations. Thus the kinetics of $\mathrm{CO}_{2}$ desorption due to air injection can be followed by pHmetry.

The desorption reaction can then be represented by the reaction 4 :

$$
\mathrm{CO}_{2(a q)}=\mathrm{CO}_{2(g)}
$$

Assuming completely stirred reactor and first order kinetics it is reasonable to write the Equation 5, which can be developed to the Equation 6:

$$
\begin{aligned}
& V \times d C / d t=-A \times k \times C \\
& \ln C=\ln C_{i}-\frac{A \times k}{V} \times t
\end{aligned}
$$

Here $C_{i}$ is the initial concentration, $\mathrm{V}$ is the aqueous solution volume, $\mathrm{k}$ is a reaction kinetic parameter, $\mathrm{A}$ is the gas-liquid interfacial area and $\mathrm{t}$ is the time. $A \times k / V$ results as a combined kinetic parameter since $A$ and $k$ can 't be evaluated separately .

Measurement of particle dispersion amid the metal is an important variable to be taken in consideration. The test consists on adding certain amount of particles $(2 \mathrm{~g} / \mathrm{L})$ and later collecting them at specified positions (Figure I, points $C$ and D) for a fixed time (I5s) through a net with its open extremity directed to azimuthal direction. Subsequently, the material is dried and weighted. The particles are made of polypropylene $\left(889 \mathrm{~kg} / \mathrm{m}^{3}\right)$ and have an average radius of $3.5 \mathrm{~mm}$.

\section{RESULTS AND DISCUSSION}

\section{I Mixing Time}

As expected the degree of mixing varies inside the reactor and steadily increases with intensification of impeller rotation. Fluid dynamics behavior on a stirred tank depends on different factors, such as impeller rotation speed, gas flow rate, impeller depth, gas injection position and others $[2,9,10]$. Even so, no remarkable difference is noticed when gas flow rate increases, Figure 3 and Figure 4. However mixing is improved for case II and III, with a mixing time reduction of $20 \%$ when compared to non-injection condition.

Cases I and II are industrially important since some reactors are built with an impeller internal gas cooling system. Thus these configurations are operationally favored and some of this gas could be diverted to injection.

Liquid inside this sort of reactor rotates pretty much as a rigid body. Due to centripetal forces considerable amount of gas dispersed inside the melt is pushed towards the longitudinal axis and then some is trapped in a conical shape underneath the impeller, Figure 5 . Air from the atmosphere can be sucked to this position specially at higher impeller velocity and smaller impeller depth of immersion [9]. Thus inert gas can be used to flush out the air avoiding metal contamination.

Lime ( $90 \%$ or more) and some sort of flux are usually added as desulfurizing agent in this type of reactor [ $\mathrm{II}$. As a result, a dry slag can be formed where diffusion can be the main obstacle to reaction. Thus a vigorous agitation is necessary to break up the products insulation layers and to expose fresh reactant surface. Gas injection can aid to that by introducing additional turbulence as measured through decreasing mixing times.
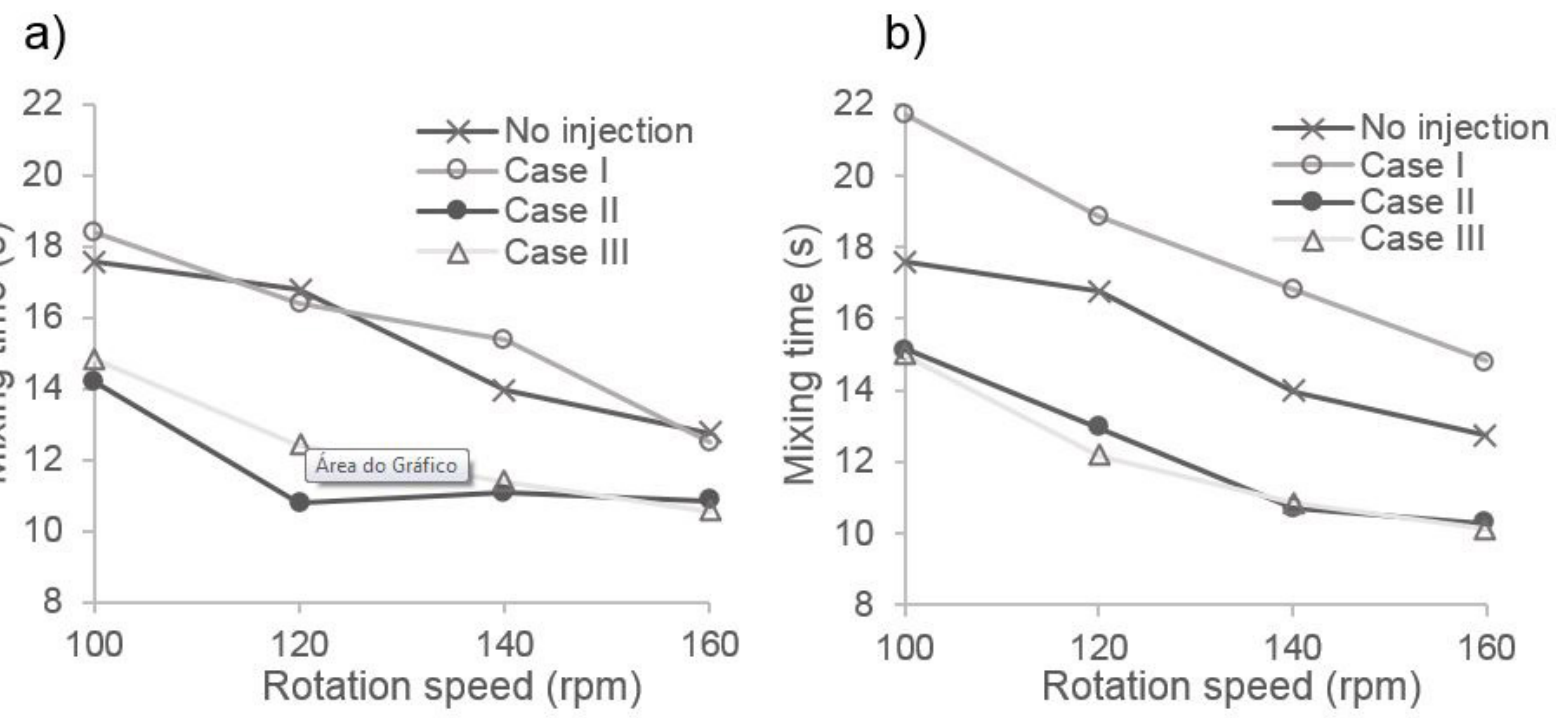

Figure 3. Mixing time at site $A$ (intermediate region of ladle). Gas flow rates: (a) IOL/min; (b) 30L/min. 
a)

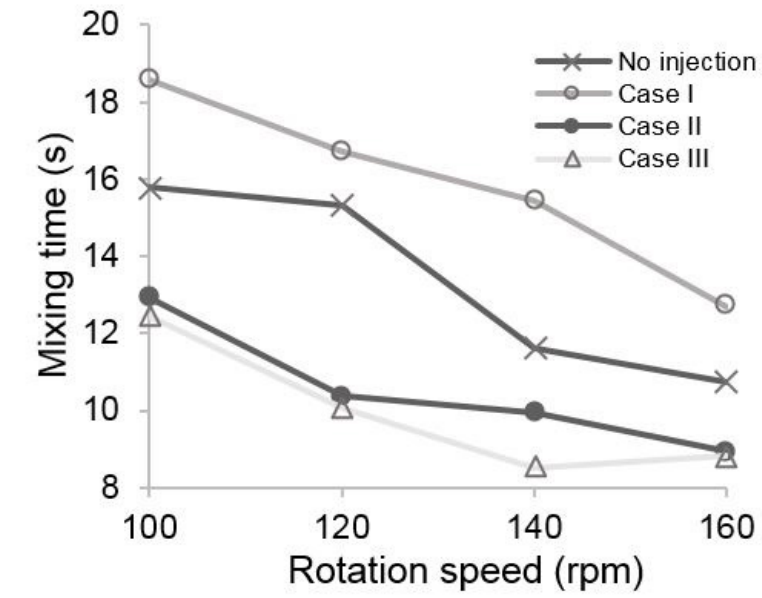

b)

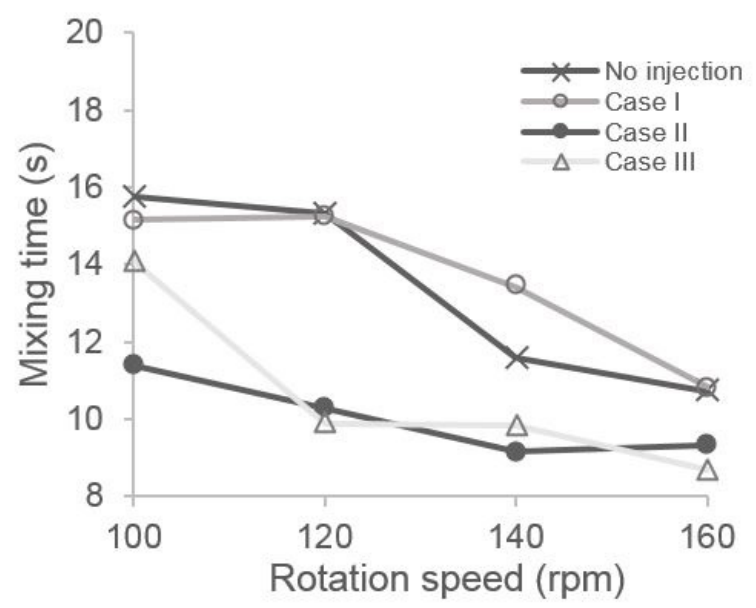

Figure 4. Mixing time at site $B$ (surface region of ladle). Gas flow rates: (a) IOL/min; (b) 30L/min.

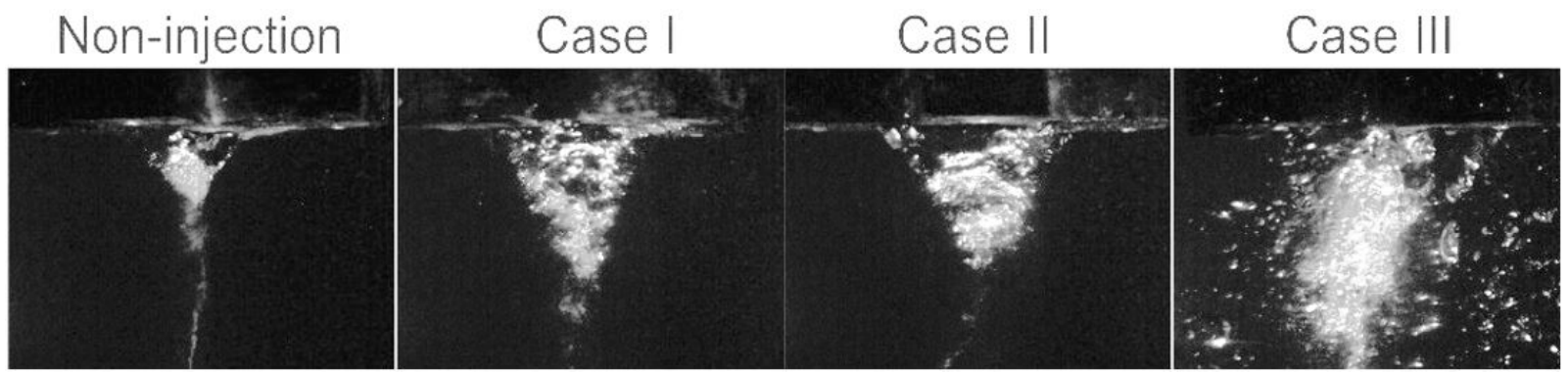

Figure 5. Gas agglomeration below impeller (100rpm and 30L/min).

\subsection{Gas/Liquid Interaction}

Gas/liquid interaction is important for reactive gas injection. In case of desulfurization by $\mathrm{Mg}$ injection, as an example, reactions occur mainly at bubbles surface [12], but some $\mathrm{Mg}$ granules can also melt or even vaporize without proper dissolution into hot metal [13]. Therefore, bubble size distribution and bubble residence time play an important role in mass transfer.

As stated in Equation 6 gas/liquid interaction can be assessed through the parameter $A \times k / V$, the slope of the $\ln [C / C]$ vs time curve.

A sample of this procedure is shown in Figure 6. It can be noticed a very satisfactory fitting as denoted by regression coefficients generally higher than 0.95 , see Figure 7. Thus, experimental consistency is assured by this technique. It results a lumped kinetic parameter $A \times k / V$ since $\mathrm{A}$ and $\mathrm{k}$ cannot be separately evaluated. However the higher the $A \times k / V$ value the faster the kinetics, the stronger the gas liquid interaction.

Figure 8 shows a comparison of the combined $A \times k / V$ kinetic parameter for different gas injection conditions (configurations I, II and III, Figure 2). Injection from ladle bottom (case III) brings the best results due to the longer residence time of gas plume in the bath. Gas injection through the bottom of the impeller (case II) was less satisfactory, certainly due to the bigger ascending bubbles between impeller blades in this case. However, in case I, where gas injection trough impeller is also employed, but by the side faces, stronger centrifugal and shear forces promote bubble disintegration and dispersion. As stated by Liu et al. [10], the tendency to increase the bubbles diameter with the gas flow rate is counterbalanced by higher impeller rotation velocities and/or shear forces conditions, which prevent bubble coalescence. Maybe for this reason, case Il presented a marginal effect on mass transfer due to gas flow rate increment.

Dissolved gas can be naturally desorbed from the bath due to interfacial turbulence effects (ripples and interface renewal) even gas injection being absent. As it is shown, injecting gas from the bottom of the impeller (case II) does not provide for an efficient gas bubble - metal contact. Most of gas-metal contact can be ascribed to the bath surface. The greater share of gas bubble - metal interaction is apparent for injection of gas from impeller lateral faces and ladle bottom. Greater residence times surely makes the difference (the effect of size distribution could not be assessed).

A reason for practicing reacting gas injection could be to maintain reducing conditions inside the bath (hydrocarbon gas injection) $[2,6]$. This sort of reactive gas injection could be effective if done from the impeller lateral faces or from ladle bottom. 


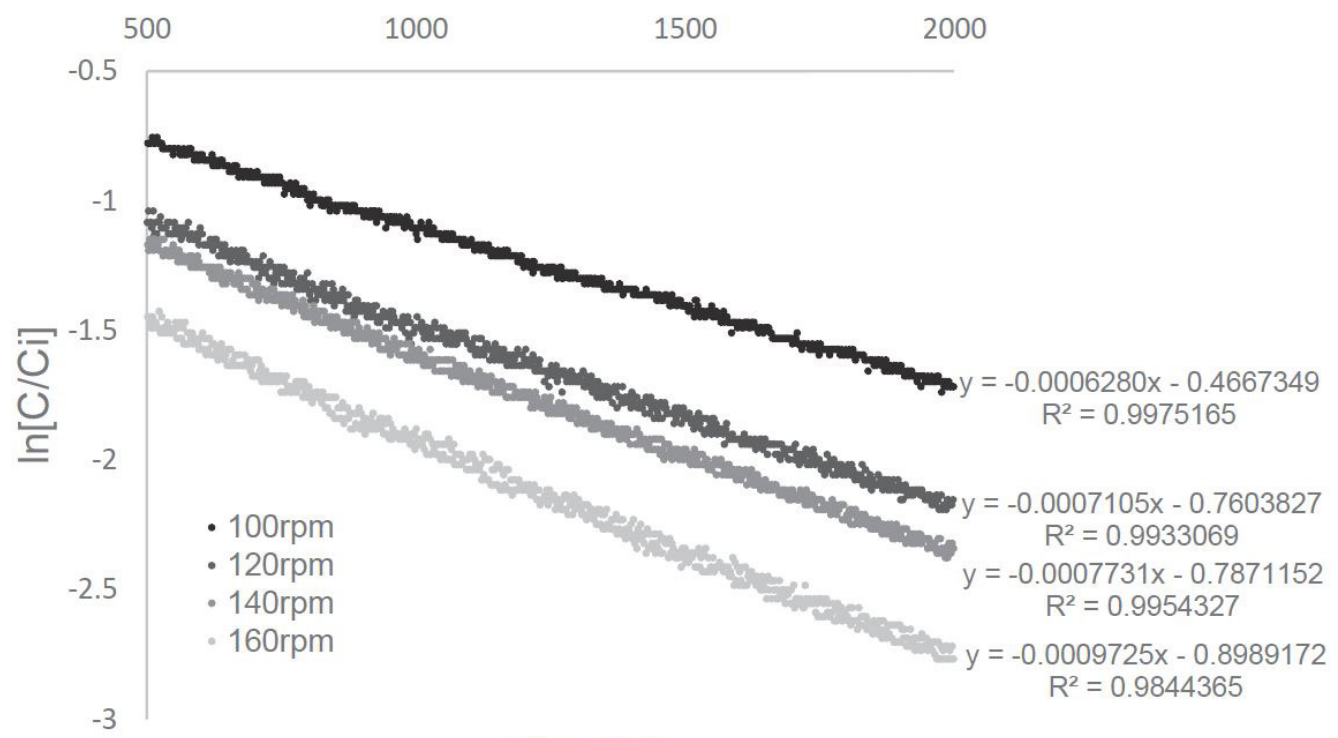

Time (s)

Figure 6. Phases interaction tests results for case I with gas flow rate of $30 \mathrm{~L} / \mathrm{min}$.

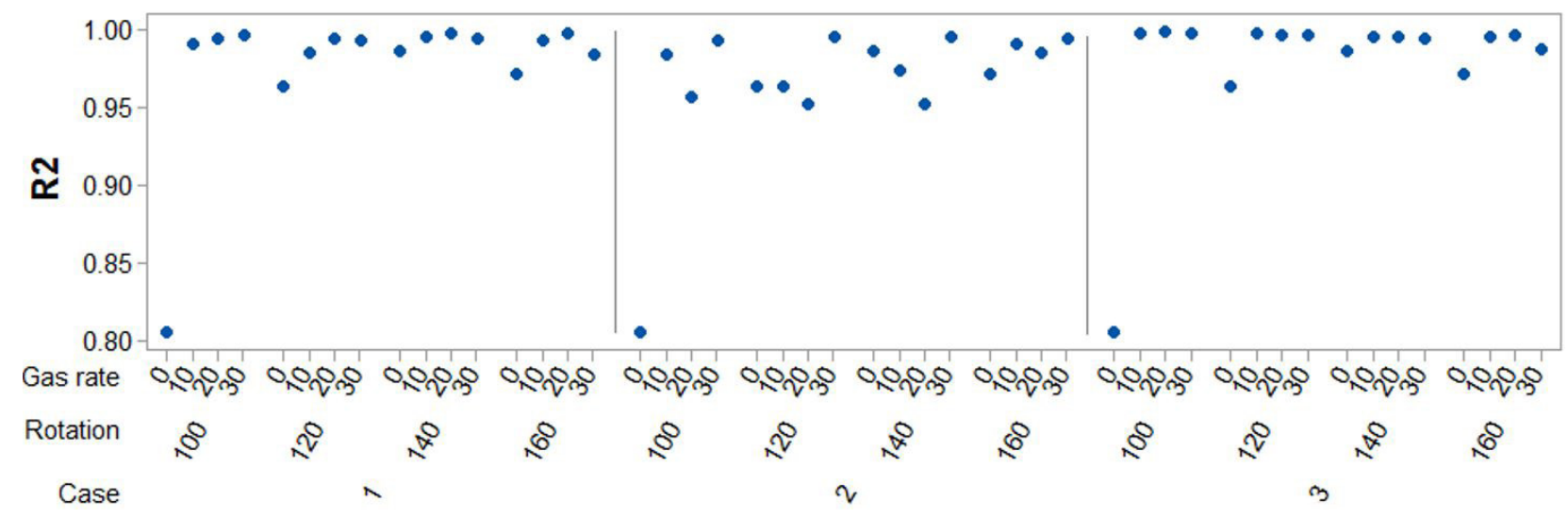

Figure 7. $R^{2}$ values of phases interaction regression curves.

a)

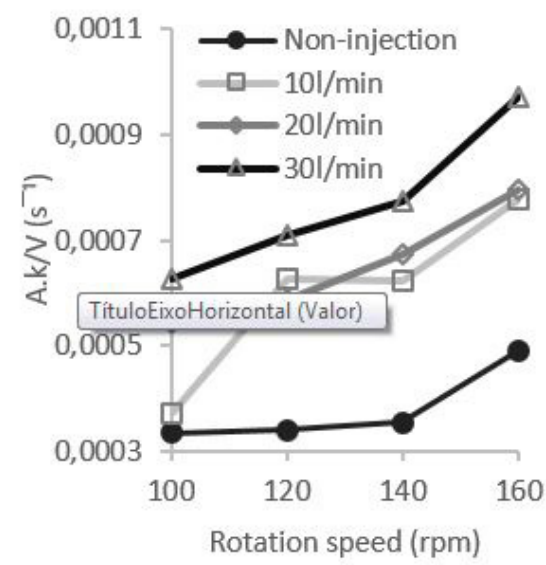

b)

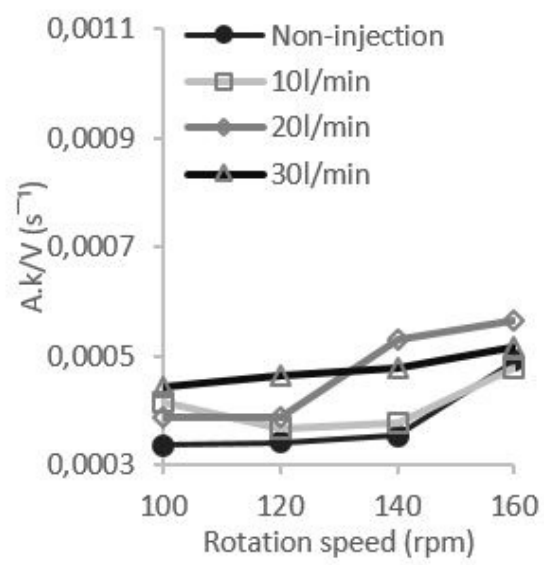

c)

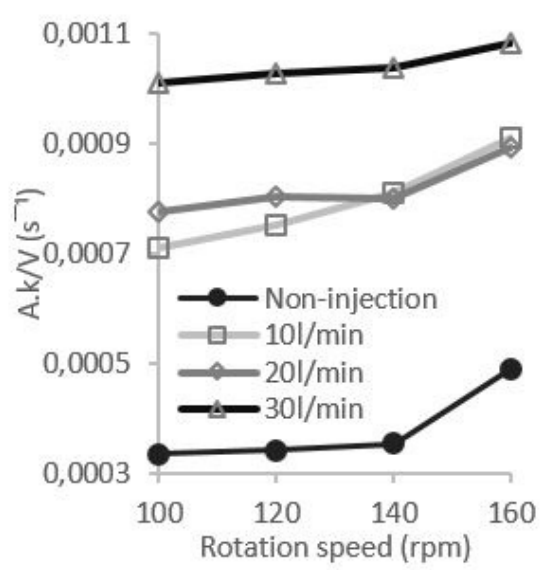

Figure 8. Comparison of $A \times k / V$ kinetic desorption parameter. (a) Case I; (b) Case II; (c) Case III. 


\subsection{Particle Dispersion Quality}

The degree of reactant dispersion can be measured by the rate of collection of particles by a net located at a given position inside the bath; this rate can be expressed as grams of particle collected by unit time, $R(\mathrm{~g} / \mathrm{s})$ and it is sensitive to position and impeller speed. This rate can normalized after division by impeller frequency, $R_{n}(g)=R(g / s) / \omega\left(s^{-1}\right)$. Particles were collected at two different levels inside the bath, as shown in Figure I: close to the bottom of the ladle, position $C$, and intermediate level, location $D$.

At the bottom of the ladle (location $\mathrm{C}$ ) the degree of dispersion seems to increase with impeller velocity, Figure 9. The same behavior was found at intermediate position (location D) as shown in Figure 10.

Figure 9 shows that the effect of gas injection seems to be potentiated by increased mechanical stirring, so that the increase in collection rate reaches $40 \%$ for the highest velocity. Since the bottom of the ladle is the most difficult area to reach, optimization of slag dispersion in this region would be of particular interest. However there is no great difference on collection rates for the increasing gas flow rates.

The (usually) dry slag is not completely dispersed in the bath; at smaller impeller velocities, some of it remains supernatant. Continuous superficial powder addition as well as powder blasting using an external lance have been proposed as a means for increasing metal - slag interaction [14]. Therefore, gas injection can be used to disturb the supernatant layer, favoring its dispersion.

Thus gas injection performance is satisfactory, since the collection of particles is greater than for non-injection condition in practically all points and rotational speeds, indicating a systemic process optimization.

Dispersion of reactant particles and particle- liquid friction are important parameters to assure metallurgical efficiency. They are related to mass transfer around each reactant particle. Gas injection does not compromise dispersion; gas injection seems to improve dispersion. a)

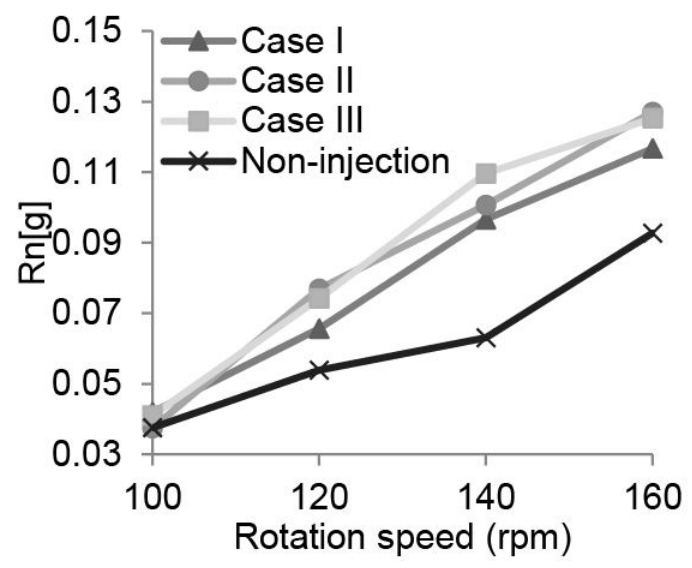

b)

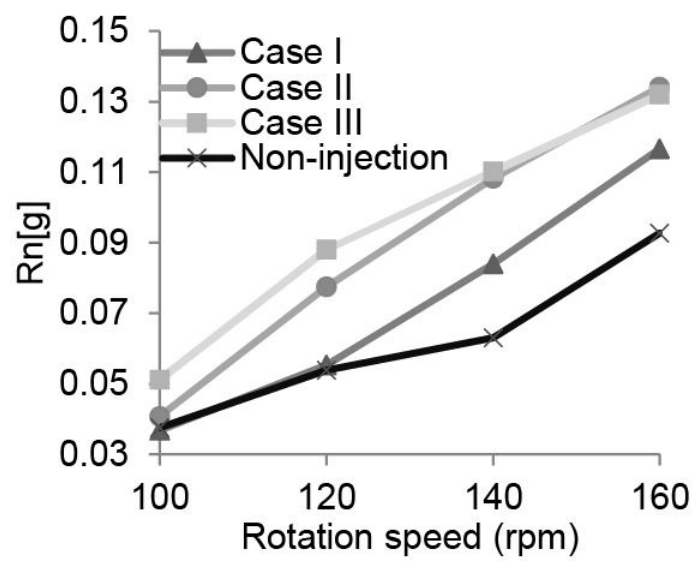

Figure 9. Normalized rate of particle collection at the bottom of ladle (location C). Gas flow rates: (a) IOL/min; (b) 30L/min.

a)

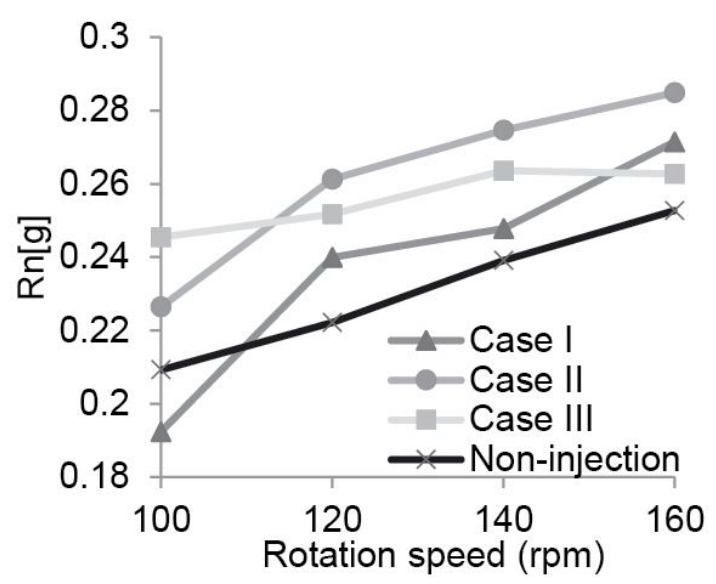

b)

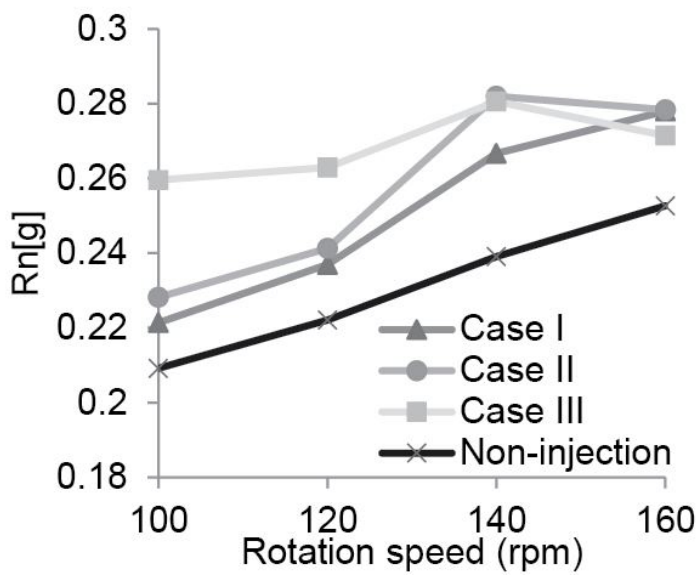

Figure 10. Normalized rate of particles collection at the intermediate position (location D). Gas flow rates: (a) IOL/min; (b) 30L/min. 


\section{CONCLUSION}

In order to optimize the efficiency of desulfurization processes, auxiliary injection of gas in a mechanical agitated system was investigated. The conclusions are as follows:

I) Gas injection through the bottom of the ladle produced the most satisfactory results as far as bubbles and liquid interfacial contact is concerned. This may be due to longer residence time of gas in this case.

2) Injection of gas by the impeller lateral walls leads to higher mass transfer rates than by the bottom of the stirrer. In the former case bubbles were better dispersed in the bath, whereas in latter case large bubbles ascended between the impeller blades impairing the contact.
3) The inert gas might contribute to removal of air sucked from atmosphere and agglomerated bellow the impeller; it could also avoid related problems, such as metal oxidation and crust formation.

4) Flux dispersion at ladle bottom can be improved by $40 \%$ if gas injection is applied. The effects seem to increase for increasing impeller rotation speeds.

5) An overall positive effect of gas injection in slag dispersion is observed compared with non-injection condition.

\section{Acknowledgements}

The authors are grateful to Capes, Fapemig, CNPq and Gorceix Foundation.

\section{REFERENCES}

I Schrama F, Berg B. Comparison of Kanbara reactor, magnesium mono-injection and lime: magnesium co-injection for hot metal desulphurization. Millennium Steel India. 20I4;4(I):26-3I.

2 Kikuchi N, Nabeshima S, Kishimoto Y. Effect of propane gas on hot metal desulfurization by CaO based flux. ISIJ International. 20I2;52(I0): I809-I8I6. http://dx.doi.org/I0.2355/isijinternational.52.I809.

3 Liu Y, Zhang Z, Liu J, Zhang J, Masamichi S, Zhang J. Cold model study on Mg desulfurization of hot metal under mechanical stirring. Journal of Iron and Steel Research. 20I3;20(I2):I-6. http://dx.doi.org/I0.10I6/SI006706X(I3)60208-3.

4 Gómez ER, Zenit R, Rivera CG, Trápaga G, Ramírez-Argáez MA. Physical modeling of fluid flow in ladles of aluminum equipped with impeller and gas purging for degassing. Metallurgical and Materials Transactions. B, Process Metallurgy and Materials Processing Science. 20 I3;44B(4):974-983. http://dx.doi.org/I0.1007/s I I663-0I3-9845-5.

5 Bird RB, Stewart WE, Lightfoot EN. Transport phenomena. 2nd ed. New York: John Wiley \& Sons; 2002.

6 Iguchi M, llegbusi OJ. Modelling multiphase materials processes: gas-liquid systems. New York: Springer; 201 I.

7 Komarov SV, Itoh K, Sano M, Blinov KA. Mixing phenomena in a liquid side and inclined nozzles bath stirred by gas jets through side inclined nozzles. ISIJ International. 1993;33(7):740-747. http://dx.doi.org/I0.2355/ isijinternational.33.740.

8 Guo D, Irons GA. Modeling of gas-liquid reactions in ladle metallurgy: part I: physical modeling. Metallurgical and Materials Transactions. B, Process Metallurgy and Materials Processing Science. 2000;3 IB(6): I447- I455. http:// dx.doi.org//0.1007/s I 1663-000-0029-8.

9 Nakai Y, Sumi I, Matsuno H, Kikuchi N, Kishimoto Y. Effect of flux dispersion behavior on desulfurization of hot metal. ISIJ International. 2010;50(3):403-4I0. http://dx.doi.org/I0.2355/isijinternational.50.403.

10 Liu Y, Sano M, Zhang TA, Wang Q, He JC. Intensification of bubble disintegration and dispersion by mechanical Stirring in gas injection refining. ISIJ International. 2009;49(I): 17-23. http://dx.doi.org/I0.2355/isijinternational.49.17.

II Gadson B, Han X. Hot metal desulphurisation: benefits of magnesium lime co-injection. Milleniun Steel. 20 10;31-36.

12 Yang J, Ozaki S, Kakimoto R, Okumura K, Kuwabara M, Sano M. Desulfurization of molten iron with magnesium vapor produced in-situ by carbothermic reduction of magnesium oxide. ISIJ International. 200 I ;4 I (9):945-954. http://dx.doi.org/I0.2355/isijinternational.4I.945.

13 Sun H, Liu Y, Lu M. Behaviour of Ar- $1 \%$ Mg bubbles in desulfurization of hot metal by magnesium injection. Steel Research International. 2009;80(3):209-217.

I4 Nakai Y, Hino Y, Sumi I, Kikuchi N, Uchida Y, Miki Y. Effect of flux addition method on hot metal desulfurization by mechanical stirring process. ISIJ International. 20I5;55(7): I398- I407. http://dx.doi.org/I0.2355/

isijinternational.55.1398.

Received: I Sept. 2016

Accepted: I Nov. 2016 